\title{
Comparable long-term efficacy, as assessed by patient-reported outcomes, safety and pharmacokinetics, of CT-P13 and reference infliximab in patients with ankylosing spondylitis: 54-week results from the randomized, parallel-group PLANETAS study
}

Won Park ${ }^{1}$, Dae Hyun Yoo ${ }^{2 *}$, Janusz Jaworski ${ }^{3}$, Jan Brzezicki ${ }^{4}$, Andriy Gnylorybov ${ }^{5}$, Vladimir Kadinov ${ }^{6}$, Irmgadt Goecke Sariego ${ }^{7}$, Carlos Abud-Mendoza ${ }^{8}$, William Jose Otero Escalante ${ }^{9}$, Seong Wook Kang ${ }^{10}$, Daina Andersone ${ }^{11}$, Francisco Blanco ${ }^{12}$, Seung Suh Hong ${ }^{13}$, Sun Hee Lee ${ }^{13}$ and Jürgen Braun ${ }^{14^{*}}$

\begin{abstract}
Background: CT-P13 (Remsima ${ }^{\oplus}$, Inflectra ${ }^{\oplus}$ ) is a biosimilar of the infliximab reference product (RP; Remicade ${ }^{\oplus}$ ) and is approved in Europe and elsewhere, mostly for the same indications as RP. The aim of this study was to compare the 54-week efficacy, immunogenicity, pharmacokinetics (PK) and safety of CT-P13 with RP in patients with ankylosing spondylitis (AS), with a focus on patient-reported outcomes (PROs).

Methods: This was a multinational, double-blind, parallel-group study in patients with active AS. Participants were randomized (1:1) to receive CT-P13 (5 mg/ $\mathrm{kg})$ or RP (5 mg/ $/ \mathrm{kg})$ at weeks $0,2,6$ and then every 8 weeks up to week 54. To assess responses, standardized assessment tools were used with an intention-to-treat analysis of observed data. Anti-drug antibodies (ADAs), PK parameters, and safety outcomes were also assessed.

Results: Of 250 randomized patients ( $n=125$ per group), 210 (84.0\%) completed 54 weeks of treatment, with similar completion rates between groups. At week 54, Assessment of Spondylo Arthritis international Society (ASAS)20 response, ASAS40 response and ASAS partial remission were comparable between treatment groups. Changes from baseline in PROs such as mean Bath Ankylosing Spondylitis Disease Activity Index (BASDAl; CT-P13 -3.1 versus RP -2.8), Bath Ankylosing Spondylitis Functional Index (BASFl; -2.9 versus -2.7), and Short Form Health Survey (SF-36) scores (9.26 versus 10.13 for physical component summary; 7.30 versus 6.54 for mental component summary) were similar between treatment groups. At 54 weeks, $19.5 \%$ and $23.0 \%$ of patients receiving CT-P13 and RP, respectively, had ADAs. All observed PK parameters of CT-P13 and RP, including maximum and minimum serum concentrations, were similar through 54 weeks. The influence of ADAs on PK was similar in the two treatment groups. Most adverse events were mild or moderate in severity. There was no notable difference between treatment groups in the incidence of adverse events, serious adverse events, infections and infusion-related reactions.

(Continued on next page)
\end{abstract}

\footnotetext{
*Correspondence: dhyoo@hanyang.ac.kr; juergen.braun@elisabethgruppe.de

${ }^{2}$ Hanyang University Hospital, Seoul, Republic of Korea

${ }^{14}$ Rheumazentrum Ruhrgebiet, Herne, Germany

Full list of author information is available at the end of the article
} 
(Continued from previous page)

Conclusions: CT-P13 and RP have highly comparable efficacy (including PROs) and PK up to week 54. Over a 1-year period, CT-P13 was well tolerated and displayed a safety profile comparable to RP; no differences in immunogenicity were observed.

Trial registration: ClinicalTrials.gov identifier: NCT01220518. Registered 4 October 2010.

Keywords: Biosimilar, CT-P13, Infliximab, Ankylosing spondylitis, Efficacy, Immunogenicity, Pharmacokinetics, Safety, ASAS, Clinical trial

\section{Background}

Infliximab is a human-murine chimeric monoclonal antibody directed against tumor necrosis factor (TNF). Originator infliximab (Remicade ${ }^{\oplus}$; hereafter referred to as the reference product (RP)) was the first TNF antagonist proven to be efficacious in patients with ankylosing spondylitis (AS) [1, 2], and is now regarded as an important component of AS care [3, 4]. However, the costs of infliximab RP and other originator biologics are often high, placing considerable financial burden on healthcare systems and, in many countries, restricting patient access [5, 6]. As a result, the development of biosimilar drugs has garnered considerable interest as many originator biologics have reached or are close to patent expiry. A biosimilar may be defined as 'a biotherapeutic product that is similar in terms of quality, safety and efficacy to an already licensed reference biotherapeutic product' [7]. Due to their assumed lower price, biosimilars have the potential to reduce costs and increase patient access and drug therapy adherence.

CT-P13 (Remsima ${ }^{\oplus}$, Inflectra ${ }^{\oplus}$ ) is a biosimilar of RP produced in the same murine hybridoma cell line as RP and approved in Europe and elsewhere for the same indications. CT-P13 and RP are identical in amino acid sequence, pharmaceutical form, strength, composition, and route of administration [8, 9]. Secondary and tertiary structures of CT-P13 and RP are highly comparable to each other, although not identical. Both drugs bind to known infliximab ligands and receptors (e.g., TNF, Fc $\gamma$ and $\mathrm{C} 1 \mathrm{q}$ ) with similar affinity, while neither bind to lymphotoxin. In vitro studies have shown that CT-P13 and RP possess equivalent TNF neutralization activity, apoptotic activity, complement-dependent cytotoxicity and antibody-dependent cellular toxicity $[8,9]$.

Biosimilar guidelines in Europe and the US state that demonstration of clinical comparability between a biosimilar and its innovator requires completion of comparator clinical trials assessing pharmacokinetics (PK), efficacy and safety $[10,11]$. Efficacy equivalence of CT-P13 and RP was established in the PLANETRA (Programme evaLuating the Autoimmune disease iNvEstigational drug cT-p13 in Rheumatoid Arthritis) study [12]. Another study called PLANETAS (Programme evaLuating the Autoimmune disease iNvEstigational drug cT-p13 in AS patients) was conducted to assess PK equivalence and comparability of efficacy and safety in patients with AS. The primary analysis of PLANETAS was performed at week 30 of the study [13]. That analysis showed that the primary endpoint of the study-PK equivalence of CT-P13 and RP as assessed by steady state area under the serum concentration curve (AUC) and maximum serum concentration $\left(\mathrm{C}_{\max }\right)$ between weeks 22 and 30 -was met. Efficacy and safety findings up to week 30 were also similar in the patients with AS.

In order to compare the extended efficacy, immunogenicity, PK and safety of CT-P13 and RP in patients with AS, PLANETAS continued up to 54 weeks (plus a subsequent off-dose period of 8 weeks). Here, we report the results of the study at week 54 .

\section{Methods}

Study methods have been reported in detail previously [13].

\section{Patients}

AS patients aged 18-75 years meeting the 1984 modified New York classification criteria [14] for $\geq 3$ months prior to screening, with Bath Ankylosing Spondylitis Disease Activity Index (BASDAI) score of $\geq 4$ (range 0-10) and a visual analogue scale score for spinal pain of $\geq 4$ (range 0-10) were eligible for the PLANETAS study. Patients were permitted to receive both oral glucocorticoids (equivalent to $\leq 10 \mathrm{mg}$ daily prednisolone) and nonsteroidal anti-inflammatory drugs, if they had received a stable dose for $\geq 4$ weeks prior to screening.

\section{Study design and treatment}

This randomized, double-blind, parallel-group study (ClinicalTrials.gov identifier: NCT01220518) was conducted in 46 centers in 10 countries. Patients were randomly assigned in a 1:1 ratio to receive CT-P13 (CELLTRION Inc, Incheon, Republic of Korea) or RP (Janssen Biotech Inc, Horsham, Pennsylvania, USA), at a dose of $5 \mathrm{mg} / \mathrm{kg}$ via 2hour intravenous infusion at weeks 0,2 and 6, and then every 8 weeks thereafter up to week 54 . Antihistamines were provided prior to infusion at the investigator's discretion. The overall randomization code was broken for regulatory reporting purposes once the database up to week 30 had been finalized for analysis [13]. However, the study 
remained blinded to the investigators and patients up to week 54 .

The study was carried out according to the principles of the Declaration of Helsinki and International Conference on Harmonisation good clinical practice guidelines. The study was approved by the relevant independent ethics committees (see Acknowledgements). All patients provided written informed consent.

\section{Study endpoints and assessments}

Efficacy was assessed at baseline and weeks 14, 30 and 54. Efficacy endpoints included: patient-reported outcomes (PROs), including BASDAI, the Bath Ankylosing Spondylitis Functional Index (BASFI), and the Short Form (36) Health Survey (SF-36); the proportion of patients achieving clinical response according to Assessment of Spondyloarthritis international Society (ASAS) 20 and ASAS40 criteria; the proportion of patients with ASAS partial remission; changes from baseline in Ankylosing Spondylitis Disease Activity Score (ASDAS)-C-reactive protein (CRP), Bath Ankylosing Spondylitis Metrology Index (BASMI) and chest expansion.

The proportion of patients who tested positive for anti-drug antibodies (ADAs) was assessed at baseline and weeks 14, 30 and 54 using an electrochemiluminescent immunoassay method, as previously reported [13]. The neutralizing activity of ADAs was also assessed by a flow-through immunoassay method utilizing the Gyros Immunoassay platform (Gyros AB, Sweden). Primary PK endpoints included the area under the concentration time curve over the dosing interval, at steady state between week 22 and week $30\left(\mathrm{AUC}_{\mathrm{T}}\right)$ and the observed maximum serum concentration at steady state between week 22 and week $30\left(\mathrm{C}_{\mathrm{max}, \mathrm{ss}}\right)$. Secondary assessments included $\mathrm{C}_{\max }$ and minimum concentration $\left(\mathrm{C}_{\min }\right)$ immediately before the next infusion up to week 54 . Blood samples were collected immediately before each treatment, at the end of each infusion, and 60 minutes post-infusion. PK analyses were performed using a flow-through immunoassay platform (Gyros AB, Sweden). The influence of ADA titer level on primary PK endpoints was assessed with a low, medium and high ADA titer based on tertile grouping of the data.

Regarding safety, adverse events (AEs) were assessed from enrollment and up to 8 weeks after last study treatment. A treatment-emergent AE (TEAE) was defined as any event not present before exposure to study treatment or an event that worsened in intensity or frequency after exposure to study treatment. Other safety assessments included vital signs monitoring, physical examination, clinical laboratory analyses, and tuberculosis (TB) monitoring. An AE of latent TB was reported if a patient had a positive result on interferon- $\gamma$ release assay after a negative result at baseline together with a negative result on chest X-ray examination. Patients were monitored for infusion-related reactions, including hypersensitivity and anaphylactic reaction.

In a series of subgroup analyses, the impact of ADA status on efficacy, PK and safety was determined. For subanalysis of ASAS20 response, ADA status was determined at week 54 . For $\mathrm{C}_{\max }$ subanalysis, a non-visit-based approach was adopted to evaluate the incidence of patients who developed ADAs up to and including week 54. In subgroup analysis of infusion-related reactions, patients were grouped according to their seroconversion status, which was defined as positive if the patient had a negative ADA test followed by a positive ADA test at a subsequent visit; all other patients who provided at least one ADA test result were included in the non-seroconverted group.

\section{Statistical analyses}

Statistical analyses were performed using Version 9.1.3 of SAS software (SAS Institute, Inc, Cary, North Carolina, USA). All efficacy analyses were performed by intention-totreat, using the 'missing equals excluded' (MEX) approach. The proportion of patients achieving clinical response (ASAS20/ASAS40) was analyzed by a logistic regression model, with treatment group as a fixed effect and the stratification factors (region and baseline BASDAI score) as covariates. Treatment effect was estimated by calculating the odds ratio (OR) and $95 \%$ confidence interval (CI). Other efficacy endpoints were analyzed using descriptive statistics.

For PK analyses, serum drug concentrations were summarized using quantitative descriptive statistics by actual treatment group, visit and time point. The PK population included patients who received at least the first five doses of study treatment, had sufficient blood concentration data to facilitate the calculation of PK parameters, and had no major protocol deviations. The safety population included all patients who received at least one (full or partial) dose of CT-P13 or RP during any dosing period.

Sensitivity analyses of ASAS response data were conducted using a last observation carried forward (LOCF) approach to compare the full-set analysis (LOCF) with the complete-case analysis (MEX).

\section{Results}

Patient disposition and baseline characteristics

Overall, 250 patients were randomly assigned to study treatment ( $\mathrm{n}=125$ in each group; Fig. 1). A total of 210 patients completed 54 weeks of treatment $(n=106$ (84.8\%) and 104 (83.2 \%) in the CT-P13 and RP groups, respectively). The most common reason for discontinuation was AEs $(\mathrm{n}=13(10.4 \%)$ and $10(8.0 \%)$, respectively) in each group.

Baseline patient demographics and disease characteristics are shown in Table 1 . In both the CT-P13 and RP 


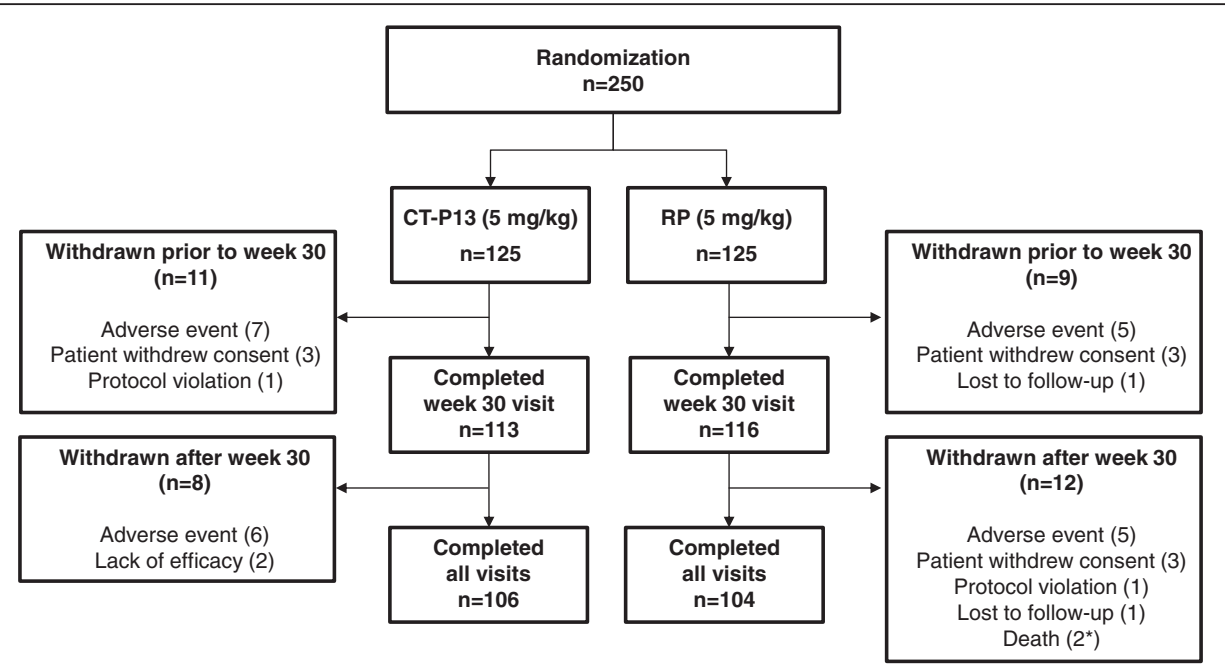

Fig. 1 Flowchart of patient disposition. A total of 250 eligible patients were randomized into the CT-P13 group $(n=125)$ or RP group ( $n=125)$ to receive $5 \mathrm{mg} / \mathrm{kg}$ of CT-P13 or RP, respectively. All 250 randomly assigned patients were included in the intention-to-treat population. *One patient randomly assigned to RP received at least one dose of CT-P13 unintentionally. RP reference product (i.e., reference infliximab)

groups the majority of patients were male $(\mathrm{n}=99$ $(79.2 \%)$ and $\mathrm{n}=103(82.4 \%)$, respectively), and median age was 38 years in both groups (range 18-69 years). Baseline scores for efficacy assessments, including PROs, were similar between groups.

\section{Efficacy}

Efficacy was similar between both treatment groups, as measured by all efficacy endpoints. The proportion of patients achieving clinical response according to ASAS20 and ASAS40 criteria at weeks 14, 30 and 54 was similar between the CT-P13 and RP groups, as were ASAS partial remission rates (Fig. 2a). Logistic regression indicated no difference in ASAS20 responses between CT-P13 and RP at week 54 (0.89 (0.50, 1.59)). Similarly, there was no difference between CT-P13 and RP for ASAS40 responses at week $54(1.26(0.73,2.15))$. Sensitivity analyses of ASAS response rates using the full-set (LOCF) population also showed no differences between CT-P13 and RP (Fig. 2b). In a subgroup analysis performed according to ADA status, the proportion of ADA-negative patients achieving ASAS20 at week 54 was $72.3 \%$ in the CT-P13 group and $73.1 \%$ in the RP group. In comparison, $47.8 \%$ and $60.0 \%$ of ADApositive patients in the CT-P13 and RP groups, respectively, achieved ASAS20 at week 54 .

ASDAS-CRP score (mean \pm standard deviation (SD)) at baseline $(3.8 \pm 0.8$ and $3.9 \pm 1.1$ in the CT-P13 and RP groups, respectively) and the mean change from baseline were similar in the CT-P13 and RP groups at week 54 $(-1.7 \pm 1.3$ and $-1.7 \pm 1.3)$.

In terms of PROs, baseline scores of BASDAI and BASFI were similar between groups, and the scores decreased from baseline up to week 54 to a similar extent in both the CT-P13 and RP groups (mean \pm SD BASDAI scores at baseline: $6.7 \pm 1.4$ versus $6.6 \pm 1.6$ in the CT-P13 and RP groups, respectively; change from baseline BASDAI scores: $-2.9 \pm 2.2$ versus $-2.8 \pm 2.1$ (week 14), $-3.0 \pm 2.2$ versus $-2.7 \pm 2.2$ (week 30 ) and $-3.1 \pm 2.3$ versus $-2.8 \pm 2.2$ (week 54 ); BASFI scores at baseline: $6.2 \pm 1.9$ versus $6.2 \pm 2.2$; change from baseline BASFI scores: $-2.5 \pm 2.1$ versus $-2.5 \pm 2.2$ (week 14 ),$-2.6 \pm 2.2$ versus $-2.5 \pm 2.2$ (week 30 ) and $-2.9 \pm 2.3$ versus $-2.7 \pm$ 2.1 (week 54)) (Fig. 3a and b). Regarding the SF-36 quality of life questionnaire, scores were similar between CT-P13 and RP groups for all components of the questionnaire at baseline and weeks 14, 30 and 54. Mean SF-36 score increased from baseline to week 54 in both groups. For the physical component summary (Fig. 3c), the mean \pm SD scores at baseline were $33.4 \pm 6.7$ and $32.2 \pm 6.8$, and at week 54 were $42.4 \pm 8.6$ and $42.2 \pm 9.0$ with CT-P13 and $\mathrm{RP}$, respectively. For the mental component summary (Fig. 3d), the mean scores at baseline were $38.1 \pm 10.3$ and $37.5 \pm 11.2$, and at week 54 were $44.9 \pm 10.9$ and $44.9 \pm$ 11.0 with CT-P13 and RP, respectively. In the CT-P13 and $\mathrm{RP}$ groups, respectively, mean change from baseline to week 54 was 9.26 and 10.13 for the physical component summary and 7.30 and 6.54 for the mental component summary.

Mean \pm SD BASMI scores and chest expansion $(\mathrm{cm})$ at baseline were $4.0 \pm 2.1$ versus $4.1 \pm 2.1$, and $3.2 \pm 1.3$ versus $2.9 \pm 1.3$ in the CT-P13 and RP groups, respectively. Mean change from baseline values were similar in the CTP13 and RP groups (week 14 : $-0.7 \pm 1.2$ versus $-0.7 \pm 1.4$; week $30:-1.0 \pm 1.4$ versus $-0.9 \pm 1.4$; week $54:-1.1 \pm 1.5$ versus $-0.9 \pm 1.6$ for BASMI (Fig. 3e); week 14: $0.4 \pm 1.0$ 
Table 1 Baseline patient demographics and disease characteristics

\begin{tabular}{|c|c|c|c|}
\hline \multirow[t]{2}{*}{ Characteristic } & \multirow{2}{*}{$\begin{array}{l}\text { CT-P13 } \\
5 \mathrm{mg} / \mathrm{kg}(\mathrm{n}=125)\end{array}$} & \multirow{2}{*}{$\begin{array}{l}\mathrm{RP} \\
5 \mathrm{mg} / \mathrm{kg}(\mathrm{n}=125)\end{array}$} & \multirow[t]{2}{*}{ Total $(n=250)$} \\
\hline & & & \\
\hline Age, years & $38.0(18-69)$ & $38.0(18-66)$ & $38.0(18-69)$ \\
\hline \multicolumn{4}{|l|}{ Gender, no. (\%) } \\
\hline Male & $99(79.2)$ & $103(82.4)$ & $202(80.8)$ \\
\hline Female & $26(20.8)$ & $22(17.6)$ & $48(19.2)$ \\
\hline \multicolumn{4}{|l|}{ Ethnicity, no. (\%) } \\
\hline Caucasian & $97(77.6)$ & $92(73.6)$ & 189 (75.6) \\
\hline Asian & $16(12.8)$ & $13(10.4)$ & $29(11.6)$ \\
\hline Other & $12(9.6)$ & $20(16.0)$ & $32(12.8)$ \\
\hline Height, cm & $172.0(148-198)$ & $171.0(147-193)$ & $172.0(147-198)$ \\
\hline Weight, kg & $72.70(45.0-120.0)$ & $76.00(45.5-122.7)$ & $73.75(45.0-122.7)$ \\
\hline Body mass index, $\mathrm{kg} / \mathrm{m}^{2}$ & $24.39(18.0-38.7)$ & $25.64(17.5-42.0)$ & $25.12(17.5-42.0)$ \\
\hline ASDAS-CRP, mean $\pm S D$ & $3.8 \pm 0.8$ & $3.9 \pm 1.1$ & $3.9 \pm 1.0$ \\
\hline \multicolumn{4}{|c|}{ BASDAI (stratification factor), no. (\%) } \\
\hline $4 \sim \leq 8$ & $92(73.6)$ & $95(76.0)$ & $187(74.8)$ \\
\hline$>8-10$ & $33(26.4)$ & $30(24.0)$ & $63(25.2)$ \\
\hline BASDAI score & $6.8(3.4-10.0)$ & $6.6(1.8-10.0)$ & $6.7(1.8-10.0)$ \\
\hline BASFI score & $6.3(0.7-9.8)$ & $6.3(0.1-10.0)$ & $6.3(0.1-10.0)$ \\
\hline BASMI score & $4.0(0.0-9.0)$ & $4.0(0.0-9.0)$ & $4.0(0.0-9.0)$ \\
\hline Chest expansion, $\mathrm{cm}$ & $3.0(0.5-9.0)$ & $2.5(0.0-7.0)$ & $3.0(0.0-9.0)$ \\
\hline \multicolumn{4}{|l|}{ SF-36 summary scores } \\
\hline Physical component & $34.1(16.2-49.7)$ & $33.1(15.3-54.3)$ & $33.4(15.3-54.3)$ \\
\hline Mental component & $38.2(15.1-63.7)$ & $37.2(12.5-63.6)$ & $37.8(12.5-63.7)$ \\
\hline $\mathrm{CRP}, \mathrm{mg} / \mathrm{dL}$ & $1.1(0.0-13.0)$ & $1.4(0.0-17.4)$ & $1.3(0.0-17.4)$ \\
\hline $\mathrm{ESR}, \mathrm{mm} / \mathrm{h}$ & $33.0(2.0-110.0)$ & $34.0(1.0-119.0)$ & $34.0(1.0-119.0)$ \\
\hline
\end{tabular}

versus $0.7 \pm 1.0$; week 30 : $0.6 \pm 1.4$ versus $0.8 \pm 1.2$; week 54: $0.7 \pm 1.4$ versus $0.9 \pm 1.1$ for chest expansion).

\section{Immunogenicity}

The proportion of patients with ADAs was similar between the CT-P13 and RP groups at each time point (week 14: $\mathrm{n}=11(8.6 \%)$ and $\mathrm{n}=13(10.7 \%)$; week 30: $\mathrm{n}=$ $32(25.0 \%)$ and $n=25$ (20.5\%); week 54: $\mathrm{n}=25(19.5 \%)$ and $n=28(23.0 \%))$. The vast majority of patients who were ADA-positive also had neutralizing activity in both the CT-13 and RP groups (week 14: $\mathrm{n}=10$ and $\mathrm{n}=13$; week 30: $n=31$ and $n=24$; week $54: n=25$ and $n=28$ ).

\section{Pharmacokinetics}

A total of $223(89.2 \%)$ patients were included in the PK population ( $n=113$ and $n=110$ in the CT-P13 and RP groups, respectively). $C_{\max }$ and $C_{\min }$ values were similar between the two treatment groups up to week 54 (Fig. 4).
The influence of ADAs on primary PK endpoints $\left(C_{\text {max,ss }}\right.$ and $\left.A U C_{\tau}\right)$ was also investigated. Figure 5 shows these endpoints by ADA titer level at week 30 in the CT-P13 and RP groups. There was a trend for both $\mathrm{C}_{\text {max,ss }}$ and $\mathrm{AUC}_{\mathrm{T}}$ to be lower with higher $\mathrm{ADA}$ titer levels. This impact of ADAs on drug exposure was similar in the two treatment groups. In a related subgroup analysis, mean (coefficient of variation) $\mathrm{C}_{\max }$ was comparable in the CT-P13 and RP groups at week 54 in both ADA-negative (142.98 (27.6) versus 135.27 (22.6) $\mu \mathrm{g} / \mathrm{mL}$, respectively) and ADA-positive (122.53 (31.1) versus $117.16(25.6) \mu \mathrm{g} / \mathrm{mL}$ ) patients.

\section{Safety}

Due to incorrect kits being dispensed, three patients randomly assigned to the RP treatment group received one dose of CT-P13 in this study. Therefore, the safety population comprised 128 and 122 patients in the CTP13 and RP groups, respectively. 


\section{a}

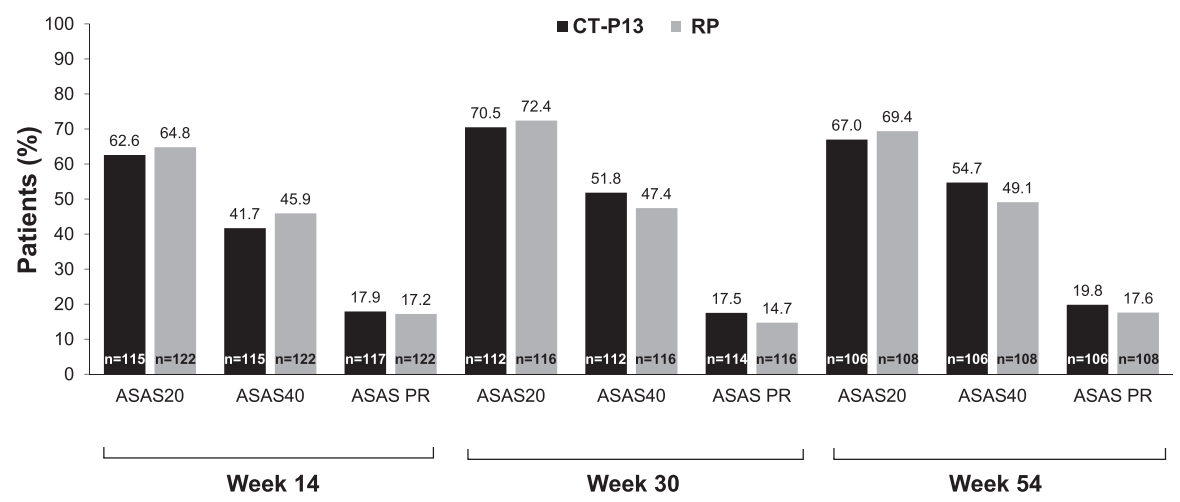

b

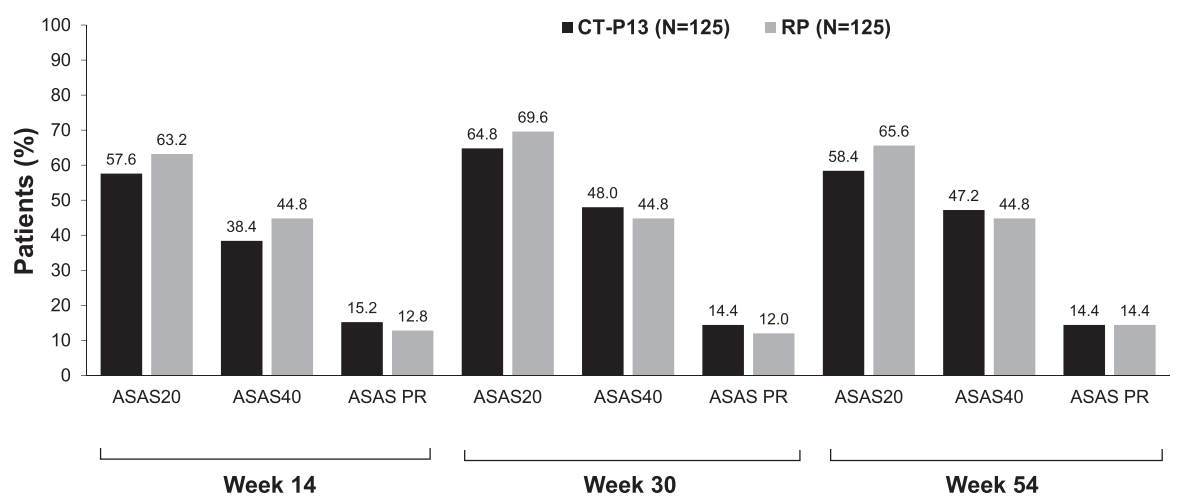

Fig. 2 Proportion of patients with an ASAS20 response, ASAS40 response and ASAS PR* up to week 54 by treatment in the a ITT population (MEX approach) and $\mathbf{b}$ ITT population (LOCF approach). " $n=$ numbers" in the bar represent the denominator of patients assessed at each time point. *PR was defined as a value of <20 on a 0-100 scale in each of the following four domains: patient global assessment, pain, function, and inflammation. ASAS Assessment of Spondylo Arthritis international Society (ASAS20 and ASAS40, $20 \%$ and $40 \%$ response according to the ASAS International Working Group criteria for improvement), ITT intention-to-treat, LOCF last observation carried forward, MEX missing equals excluded, $P R$ partial remission, $R P$ reference product (i.e. reference infliximab)

The proportion of patients who experienced at least one TEAE was similar in the CT-P13 and RP groups $(\mathrm{n}=95(74.2 \%)$ and $82(67.2 \%)$, respectively). Most TEAEs were mild or moderate in intensity. TEAEs considered by the investigator to be related to study treatment were reported in $64(50.0 \%)$ and $63(51.6 \%)$ patients, respectively. The most common of these events are shown in Table 2. Related TEAEs occurring in $>4 \%$ of patients were (for CT-P13) abnormal liver function test $(\mathrm{n}=16$ $(12.5 \%))$, upper respiratory tract infection $(n=12(9.4 \%))$, infusion-related reaction $(\mathrm{n}=11(8.6 \%))$ and latent TB $(9$ $(7.0 \%))$, and (for RP) abnormal liver function test $(\mathrm{n}=15$ $(12.3 \%))$, infusion-related reaction $(\mathrm{n}=15(12.3 \%))$, upper respiratory tract infection $(\mathrm{n}=8(6.6 \%))$ and latent TB $(6$ $(4.9 \%))$. Infusion-related reactions affected more ADApositive than ADA-negative patients in both treatment groups (CT-P13: 6/44 (13.6\%) versus 5/84 (6.0 \%); RP: 11/ $39(28.2 \%)$ versus $4 / 83(4.8 \%))$.
Two cases of active TB were reported in the CT-P13 group and one case was reported in the RP group. A single case of malignancy, which was considered to be unrelated to treatment, was reported in the CT-P13 group (basal cell carcinoma). The onset date of this event was unknown, but was believed to have started 2 years previously, based on the medical history of the patient (melanocyte nevus). Treatment for the event was excision of a skin nodule of the nose. The event was considered to have recovered/resolved according to the investigator.

The proportion of patients who experienced at least one serious AE (SAE) was similar between the CT-P13 and RP groups $(\mathrm{n}=10(7.8 \%)$ and $8(6.6 \%)$, respectively), as was the proportion who had an SAE considered related to treatment $(\mathrm{n}=4(3.1 \%)$ and $5(4.1 \%)$; see Additional file 1 for details of treatment-related SAEs). The number of patients with at least one TEAE leading to discontinuation was comparable between the CT-P13 


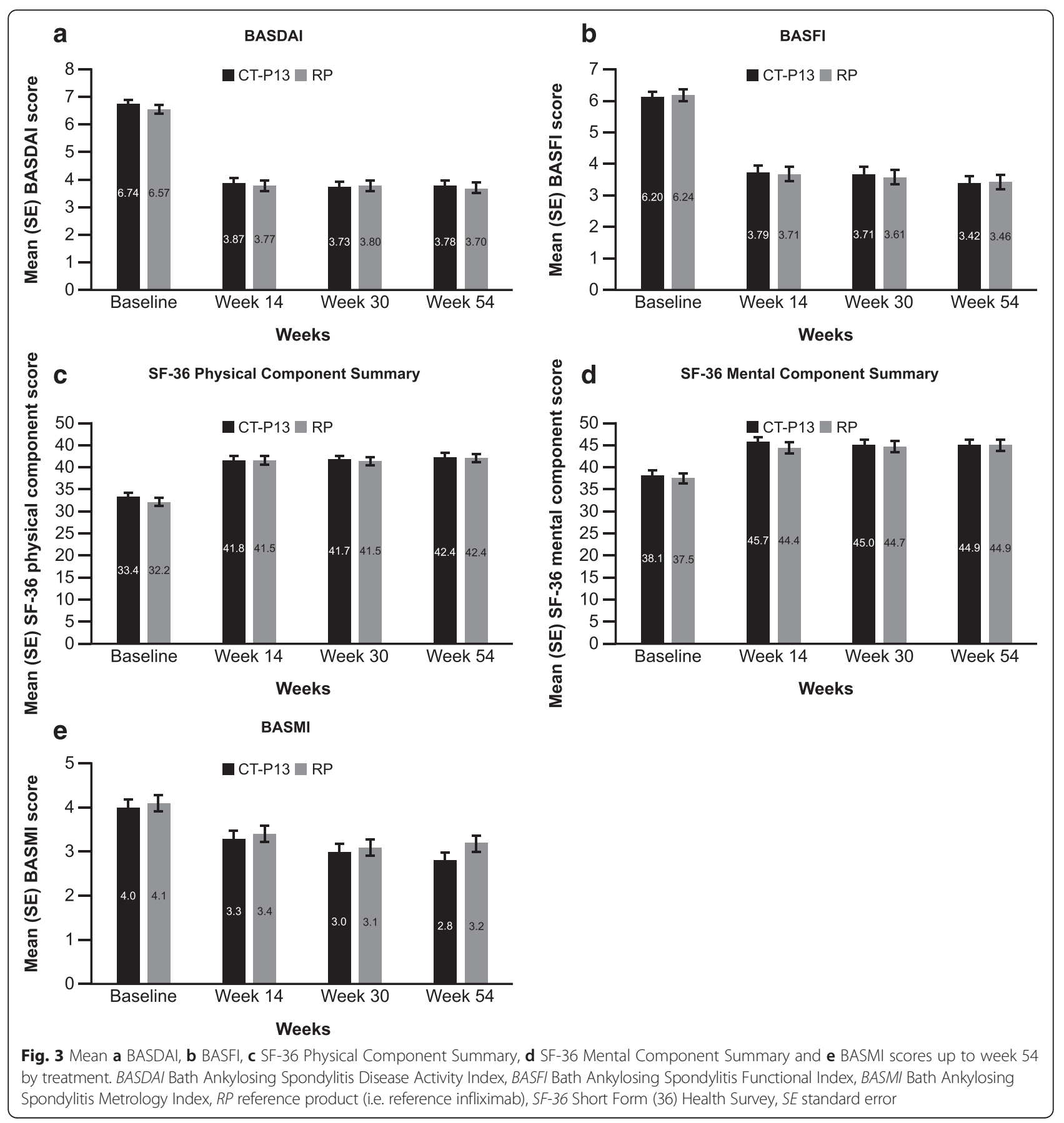

and RP groups $(\mathrm{n}=11(8.6 \%)$ and $9(7.4 \%)$, respectively). Of these, $9(7.0 \%)$ and 7 (5.7 \%) were considered to be related to CT-P13 and RP, respectively. Overall, treatment-related events leading to discontinuation of more than one patient were TB in two patients from the CT-P13 group and one in the RP group, two abnormal liver function tests (one in each group), and infusionrelated reactions in one patient from the CT-P13 group and five from the RP group. Two deaths occurred during the study, one in each treatment group. Both were due to car accidents and were considered not related to study treatment.

\section{Discussion}

PLANETAS was a multinational, randomized, doubleblind biosimilar study that evaluated the equivalence of PK and comparability of efficacy and safety between CTP13 and RP up to 54 weeks in patients with active AS.

Similar clinical efficacy was observed between CT-P13 and RP up to week 54. ASAS responses at weeks 30 and 


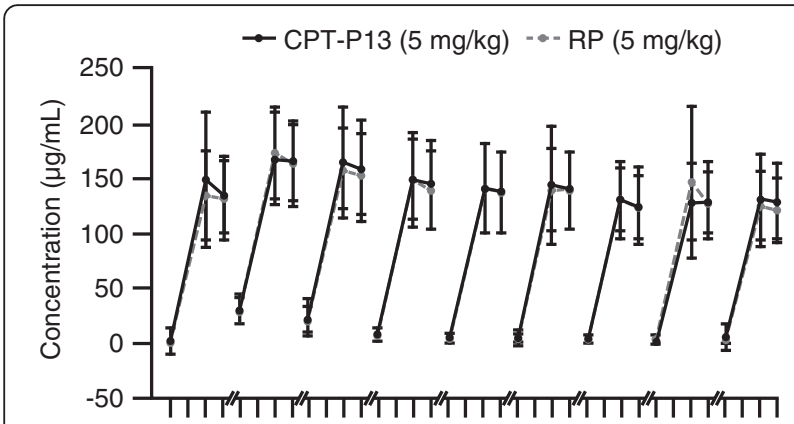

Hour: 012301230123012301230123012301230123

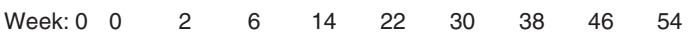

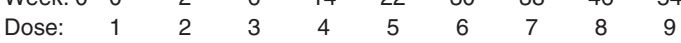

Fig. 4 Mean (SD) serum PK parameters of CT-P13 and RP (PK population). Note: values below the LLOQ have been set equal to the LLOQ. LLOQ lower limit of quantification, $P K$ pharmacokinetics, $R P$ reference product (i.e. reference infliximab), SD standard deviation

54, respectively, were comparable in the two treatment groups. PROs-including mean BASDAI, BASFI and SF36 scores-and other efficacy endpoints such as BASMI score and chest expansion were also similar in both treatment groups up to week 54. The similarity in PROs is notable because, unlike the other efficacy endpoints employed in the study, these are patient-led evaluations.

Thirty-week efficacy data in PLANETAS were comparable to 24-week data from a pivotal placebo-controlled clinical study of RP in AS (ASSERT) [2, 13]. Analogously, the efficacy data seen here for CT-P13 at week 54 are in line with findings previously reported for RP in different clinical trials with a similar duration [15-17]. For example, in the current analysis, the ASAS20 responses and improvement of BASDAI and BASFI scores with CT-P13 at 54 weeks were $67 \%, 3.1$ and 2.9 , respectively. Similar improvements in these measurements were also observed at weeks $48-58$ in historical studies with RP (ASAS20 at week $58=75 \%$; BASDAI from 6.6 at week 0 to 2.4 at week 54; BASFI from 6.1 at baseline to 4.4 at week 48) [15-17]. While there are inherent limitations associated with comparing across trials due to differences in patient populations and methods, it is reassuring that the data for CT-P13 are generally in line with historical observations for RP. Long-term efficacy equivalence of CT-P13 and RP has also been established in a 54-week analysis of the PLANETRA study in rheumatoid arthritis (RA). An American College of Rheumatology (ACR) 20 response was achieved in a highly similar proportion of patients treated with CT-P13 and RP [18].

The long-term PK profiles $\left(\mathrm{C}_{\max }\right.$ and $\left.\mathrm{C}_{\min }\right)$ of CT-P13 and RP were similar to each other in the current study through to week 54 . The $\mathrm{C}_{\max }$ data reported here are consistent with PLANETAS data reported at 30 weeks and those of studies adopting a similar RP dosing pattern in Crohn's disease [13, 19]. Similarity of PK was also observed between CT-P13 and RP in patients with RA in the PLANETRA study $[12,18]$.

CT-P13 was well tolerated up to week 54, with a safety profile comparable to that of RP. As previously reported at week 30 for PLANETAS [13], there was no notable difference between study arms in the incidence of AEs, SAEs, infections and infusion-related reactions; this trend continued up to week 54 . The safety profile observed with CT-P13 in the current study is also generally aligned with the safety profile of RP in historical studies involving patients with AS and RA [1, 2, 15-17, 20-29]. One treatment-unrelated case of basal cell carcinoma was reported with CT-P13. It is believed that the malignancy started 2 years prior to study participation. Following appropriate treatment (excision), the event was considered to have resolved.

It is well documented that development of ADAs against infliximab is associated with decreased clinical response and drug serum concentration [13, 30-32]. We also observed lower ASAS20 response rates and lower $\mathrm{C}_{\max }$ values at week 54, as well as a higher incidence of infusion-related reactions in ADA-positive compared with ADA-negative patients. These ADA effects were comparable in both the CT-P13 and RP groups. Further
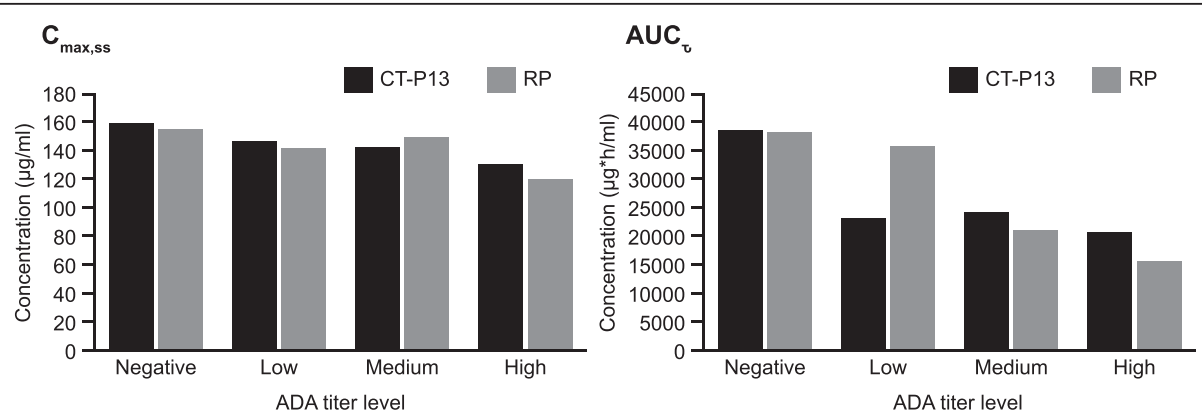

Fig. 5 Primary PK parameters ( $C_{\max , s s}$ and $A U C_{T}$ ) by ADA titer level at week 30 (PK population). Note: titer levels were defined as low, medium and high titer based on tertile grouping of the data. $A D A$ anti-drug antibodies, $A U C_{T}$ area under the concentration time curve over the dosing interval, at steady state between week 22 and week $30, C_{\text {max,ss }}$ the observed maximum serum concentration at steady state between week 22 and week 30, PK pharmacokinetics, $R P$ reference product (i.e. reference infliximab) 
Table 2 Treatment-related adverse events reported in at least $1 \%$ of all (total) patients, n (\%)

\begin{tabular}{|c|c|c|c|}
\hline & $\begin{array}{l}\text { CT-P13 } \\
(n=128)\end{array}$ & $\begin{array}{l}\mathrm{RP} \\
(\mathrm{n}=122)\end{array}$ & $\begin{array}{l}\text { Total } \\
\text { CT-P13 + RP }(n=250)\end{array}$ \\
\hline Abnormal liver function test & $16(12.5)$ & $15(12.3)$ & $31(12.4)$ \\
\hline Infusion-related reaction & $11(8.6)$ & $15(12.3)$ & $26(10.4)$ \\
\hline Upper respiratory tract infection & $12(9.4)$ & $8(6.6)$ & $20(8.0)$ \\
\hline Latent tuberculosis & $9(7.0)$ & $6(4.9)$ & $15(6.0)$ \\
\hline Urinary tract infection & $5(3.9)$ & $4(3.3)$ & $9(3.6)$ \\
\hline Neutropenia & $4(3.1)$ & $3(2.5)$ & $7(2.8)$ \\
\hline Elevated serum creatine phosphokinase & $4(3.1)$ & $2(1.6)$ & $6(2.4)$ \\
\hline Rash & $2(1.6)$ & $4(3.3)$ & $6(2.4)$ \\
\hline Headache & $3(2.3)$ & $1(0.8)$ & $4(1.6)$ \\
\hline Herpes virus infection & $1(0.8)$ & $3(2.5)$ & $4(1.6)$ \\
\hline Sinusitis & $2(1.6)$ & $1(0.8)$ & $3(1.2)$ \\
\hline Tuberculosis & $2(1.6)$ & $1(0.8)$ & $3(1.2)$ \\
\hline
\end{tabular}

$R P$ reference product (i.e. reference infliximab)

analysis of $\mathrm{PK}$ parameters with respect to ADA levels found a trend for both $\mathrm{AUC}_{\mathrm{T}}$, and $\mathrm{C}_{\max , \mathrm{ss}}$ to be lower with increasing ADA titer level, although a formal statistical inference was not made due to a limited statistical power.

Further extensions of the current study and the PLANETRA study were conducted to examine the efficacy and safety of switching treatment from RP to CT-P13 in patients with AS and RA, respectively. Additionally, a formal randomized double-blind 'switching' clinical trial is currently progressing in Norway. This trial ('NORSWITCH'; ClinicalTrials.gov identifier: NCT02148640) is comparing the safety and efficacy of switching from RP to CT-P13 versus continued treatment with RP in several indications, including RA. Data from the PLANETAS/PLANETRA extensions and NOR-SWITCH will provide further evidence on the ability to switch from RP to CT-P13.

The main limitation of this analysis is that PLANETAS was primarily designed to compare the PK profiles of CT-P13 and RP at 30 weeks. While prospectively planned, the longer-term efficacy, safety and PK data presented here are from a secondary analysis of the study.

\section{Conclusions}

This multinational, randomized, biosimilar study in patients with active AS demonstrated that CT-P13 and RP have highly comparable efficacy, safety, immunogenicity and PK profiles up to week 54. Together with the findings from the PLANETRA study in patients with RA, these data further demonstrate the similarity between CT-P13 and RP in diverse clinical settings.

\section{Additional file}

Additional file 1: Overview of treatment-related SAEs occurring by severity, $\mathbf{n}(\%)$. (DOC $31 \mathrm{~kb})$

\section{Abbreviations}

ADA: Anti-drug antibody; AE: Adverse event; AS: Ankylosing spondylitis; ASAS: Assessment of Spondylo Arthritis international Society; ASDAS: Ankylosing Spondylitis Disease Activity Score; AUC: Area under the curve; $A \cup C_{\mathrm{T}}$ : Area under the concentration time curve over the dosing interval, at steady state between week 22 and week 30; BASDAl: Bath Ankylosing Spondylitis Disease Activity Index; BASFI: Bath Ankylosing Spondylitis Functional Index; BASMl: Bath Ankylosing Spondylitis Metrology Index; Cl: Confidence interval; $C_{\text {max }}$ : Maximum serum concentration; $C_{\max , s}$ : Maximum serum concentration at steady state between week 22 and week 30; $C_{\text {min: }}$ : Minimum serum concentration; CRP: C-reactive protein; LOCF: Last observation carried forward; MEX: Missing equals excluded; OR: Odds ratio; PK: Pharmacokinetics; PRO: Patient-reported outcome; RA: Rheumatoid arthritis; RP: Reference product; SAE: Serious adverse event; SD: Standard deviation; SF-36: Short Form (36) Health Survey; TB: Tuberculosis; TEAE: Treatment-emergent adverse event; TNF: Tumor necrosis factor.

\section{Competing interests}

DHY and WP: Consultation for CELLTRION. FB reports consultancy fees from Gebro Pharma, and grants from Bioiberica, MSD, GSK, UCB, Roche, Pfizer, Celgene, Amgen, Grunenthal, Sanofi, Tedec-Meiji, and lecture fees from Bioiberica. SSH and SHL are full-time employees of CELLTRION. JBra has received honoraria for talks, advisory boards, paid consultancies or grants for studies from Abbvie (Abbott), Amgen, Boehringer Ingelheim, Bristol-Myers-Squibb, Celgene, CELLTRION, Centocor, Chugai, EBEWE Pharma, Janssen, Medac, MSD (Schering-Plough), Mundipharma, Novartis, Pfizer (Wyeth), Roche, Sanofi-Aventis and UCB. All other authors declare that they have no competing interests.

\section{Authors' contributions}

WP, DHY, JBra, SSH and SHL were involved in the conception and design of the study, and/or analysis and interpretation of data; drafting of the manuscript and revising it critically for important intellectual content; and final approval of the version to be published. JJ, JBrz, AG, VK, IGS, CA-M, WJOE, SWK, DA and FB were involved in the acquisition of data; drafting of the manuscript and revising it critically for important intellectual content; and final approval of the version to be published. 


\section{Acknowledgements}

The authors wish to thank the patients and study personnel who made this trial possible, and the PLANETAS study investigators: Bulgaria; Rashkov R; Chile; Aguirre V, Gutierrez M, Miranda P; Korea (Republic of ); Kim HY, Kim TH, Lee YA, Lim MJ, Park YB, Park YE, Song JS, Suh CH; Latvia; Mikazane H, Saulite-Kandevica D; Mexico; Araiza R, Cons Molina F, Morales-Torres J, Pacheco-Tena C, Gutierrez-Ureña S; Poland; Brzosko M, Hrycaj M, Jeka S, Korkosz M, Krogulec M, Piotrowski M, Ruzga Z, Wiland P; Portugal; Vaz Patto J; Spain; Díaz-González F; Ukraine; Amosova K, Dyadyk O, Kovalenko V, Lysenko G, Smiyan S, Ter-Vartanian S; USA; Ahn C.

The following ethical bodies approved the study in the centers involved: Bulgaria: Ethics Committee for Multi-centre Trials; Chile: Comité de Ética en Investigación Escuela de Medicina Pontificia Universidad Católica de Chile; Comite de Evaluacion de Etica Cientifico del Servicio de Salud Metropolitano Oriente; Comite de Etica de la Investigacion Servicio de Salud Valdivia; Colombia: Comité de Ética en Investigación Servimed; Comite de Etica de la Investigacion Riesgo de Fractura SA; Latvia: The Ethics Committee for Clinical Trials on Medicinal Products; Mexico: Comite de Investigacion y Etica del Hospital Central "Dr. Ignacio Morones Prieto"; Comité de Ética e Investigación Christus Muguerza del Parque SA de CV; Comite Bioetico para la Investigacion Clinica S.C. Institutional Review Board; Comité de Enseñanza, Investigación y Ética del Hospital Civil de Guadalajara Fray Antonio Alcalde; Comité de Etica e Investigación del Hospital Aranda de la Parra; Poland: Komisja Bioetyczna przy Okregowej Radzie Lekarskiej Wielkopolskiej Izby Lekarskiej w Poznaniu; Portugal: Comissão de Ética para a Investigação Clinica; Republic of Korea: Inha University Hosiptal IRB; Chungnam National University Hospital Institutional Review Board: Pusan National University Hospital Institutional Review Board; HanYang University Medical Center IRB; Kyung Hee University Medical Center IRB; Chung-Ang University Hospital IRB; IRB of Seoul St. Mary's Hospital, The Catholic University; Severance Hospital Institutional Review Board; Ajou University Hospital Institutional Review Board; Spain: CEIC de Galicia (SERGAS); CEIC Hospital Universitario de Canarias; Ukraine: Central Commission on Ethics Questions of the MoH of Ukraine. This work was funded by CELLTRION Inc. The funding body contributed to the design of the study and the collection, analysis, and interpretation of data; and reviewed drafts and the final version of the manuscript. The final decision to submit the manuscript was taken by the authors. Editorial support (writing assistance, assembling tables and figures, collating author comments, grammatical editing and referencing) was provided by Rick Flemming (Aspire Scientific Limited, Bollington, UK) and was funded by CELLTRION Healthcare Co., Ltd (Incheon, Republic of Korea).

\section{Author details}

${ }^{1}$ Inha University Hospital, Incheon, Republic of Korea. ${ }^{2}$ Hanyang University Hospital, Seoul, Republic of Korea. ${ }^{3}$ Linea Corporis, Warszawa, Poland. ${ }^{4}$ Wojewodzki Szpital Zespolony w Elblagu, Elblag, Poland. ${ }^{5}$ Institute of Urgent and Recovery Surgery, Donetsk, Ukraine. ${ }^{6}$ University Hospital St. Marina, Varna, Bulgaria. ${ }^{7}$ Prosalud y Cia Ltda, Santiago, Chile. ${ }^{8}$ Hospital Central Dr. Ignacio Morones Prieto, San Luis Potosí, Mexico. ${ }^{9}$ Servimed Empresa Unipersonal, Bucaramanga, Colombia. ${ }^{10}$ Chungnam National University Hospital, Daejeon, Republic of Korea. ${ }^{11}$ P. Stradina Clinical University Hospital, Riga, Latvia. ${ }^{12}$ Hospital Universitario a Coruña, A Coruña, Spain. ${ }^{13}$ CELLTRION, Incheon, Republic of Korea. ${ }^{14}$ Rheumazentrum Ruhrgebiet, Herne, Germany.

Received: 5 October 2015 Accepted: 8 January 2016

Published online: 20 January 2016

\section{References}

1. Braun J, Brandt J, Listing J, Zink A, Alten R, Golder W, et al. Treatment of active ankylosing spondylitis with infliximab: a randomised controlled multicentre trial. Lancet. 2002;359:1187-93.

2. van der Heijde D, Dijkmans B, Geusens P, Sieper J, DeWoody K, Williamson P, et al. Efficacy and safety of infliximab in patients with ankylosing spondylitis: results of a randomized, placebo-controlled trial (ASSERT). Arthritis Rheum. 2005:52:582-91.

3. van der Heijde D, Sieper J, Maksymowych WP, Dougados M, Burgos-Vargas R, Landewe R, et al. 2010 Update of the international ASAS recommendations for the use of anti-TNF agents in patients with axial spondyloarthritis. Ann Rheum Dis. 2011;70:905-8.

4. Braun J, van den Berg R, Baraliakos X, Boehm H, Burgos-Vargas R, CollantesEstevez $\mathrm{E}$, et al. 2010 update of the ASAS/EULAR recommendations for the management of ankylosing spondylitis. Ann Rheum Dis. 2011;70:896-904.
5. Nast A, Mrowietz U, Kragballe K, de Jong EM, Puig L, Reich K, et al. Barriers to the prescription of systemic therapies for moderate-to-severe psoriasis - a multinational cross-sectional study. Arch Dermatol Res. 2013;305:899-907.

6. Putrik P, Ramiro S, Kvien TK, Sokka T, Pavlova M, Uhlig T, et al. Inequities in access to biologic and synthetic DMARDs across 46 European countries. Ann Rheum Dis. 2014;73:198-206.

7. World Health Organization. Expert Committee on Biological Standardization. Guidelines on evaluation of similar biotherapeutic products (SBPs). 2009. Available at: http://www.who.int/biologicals/areas/biological_therapeutics/ BIOTHERAPEUTICS_FOR_WEB_22APRIL2010.pdf. Accessed 19 Feb 2015.

8. European Medicines Agency. Committee for Medicinal Products for Human Use (CHMP). Assessment report: Remsima (infliximab). 2013. Available at: http://www.ema.europa.eu/docs/en_GB/document_library/ EPAR_-_Public_assessment_report/human/002576/WC500151486.pdf. Accessed 19 Feb 2015.

9. Jung SK, Lee KH, Jeon JW, Lee JW, Kwon BO, Kim YJ, et al. Physicochemical characterization of Remsima ${ }^{\oplus}$. mAbs. 2014;6:1163-77.

10. European Medicines Agency. Committee for Medicinal Products for Human Use (CHMP). Guideline on Similar Biological Medicine Products (CHMP/437/ 04 Rev 1). 23 October 2014. Available at: http://www.ema.europa.eu/docs/ en_GB/document_library/Scientific_guideline/2014/10/WC500176768.pdf. Accessed 2 July 2015.

11. U.S. Department of Health and Human Services; Food and Drug Administration; Center for Drug Evaluation and Research (CDER); Center for Biologics Evaluation and Research (CBER). Scientific Considerations in Demonstrating Biosimilarity to a Reference Product. Guidance for Industry. April 2015. Available at: http://www.fda. gov/downloads/Drugs/GuidanceComplianceRegulatory/nformation/Guidances/ UCM291128.pdf. Accessed 2 July 2015.

12. Yoo DH, Hrycaj P, Miranda P, Ramiterre E, Piotrowski M, Shevchuk S, et al. A randomised, double-blind, parallel-group study to demonstrate equivalence in efficacy and safety of CT-P13 compared with innovator infliximab when coadministered with methotrexate in patients with active rheumatoid arthritis: the PLANETRA study. Ann Rheum Dis. 2013;72:1613-20.

13. Park W, Hrycaj P, Jeka S, Kovalenko V, Lysenko G, Miranda P, et al. A randomised, double-blind, multicentre, parallel-group, prospective study comparing the pharmacokinetics, safety, and efficacy of CT-P13 and innovator infliximab in patients with ankylosing spondylitis: the PLANETAS study. Ann Rheum Dis. 2013;72:1605-12.

14. van der Linden S, Valkenburg HA, Cats A. Evaluation of diagnostic criteria for ankylosing spondylitis. A proposal for modification of the New York criteria. Arthritis Rheum. 1984;27:361-8.

15. Braun J, Brandt J, Listing J, Zink A, Alten R, Burmester G, et al. Long-term efficacy and safety of infliximab in the treatment of ankylosing spondylitis: an open, observational, extension study of a three-month, randomized, placebo-controlled trial. Arthritis Rheum. 2003;48:2224-33.

16. Breban M, Ravaud P, Claudepierre P, Baron G, Henry YD, Hudry C, et al. Maintenance of infliximab treatment in ankylosing spondylitis: results of a one-year randomized controlled trial comparing systematic versus ondemand treatment. Arthritis Rheum. 2008:58:88-97.

17. Giardina AR, Ferrante A, Ciccia F, Impastato R, Miceli MC, Principato A, et al. A 2-year comparative open label randomized study of efficacy and safety of etanercept and infliximab in patients with ankylosing spondylitis. Rheumatol Int. 2010;30:1437-40

18. Yoo DH, Racewicz A, Brzezicki J, Yatsyshyn R, Tobias-Arteaga E, Baranauskaite $\mathrm{A}$, et al. A phase 3 randomised controlled trial to compare CT-P13 with infliximab in patients with active rheumatoid arthritis: 54 week results from the PLANETRA study. Ann Rheum Dis. 2013;72 Suppl 3:73 [OP0068].

19. US Food and Drug Administration. Infliximab Product Approval Information: Clinical Pharmacology Review 1999; Available at: http://www.fda. gov/downloads/Drugs/DevelopmentApprovalProcess/HowDrugsareDeveloped andApproved/ApprovalApplications/TherapeuticBiologicApplications/ ucm107725.pdf. Accessed 20 Feb 2015

20. Maini RN, Breedveld FC, Kalden JR, Smolen JS, Davis D, Macfarlane JD, et al. Therapeutic efficacy of multiple intravenous infusions of anti-tumor necrosis factor alpha monoclonal antibody combined with low-dose weekly methotrexate in rheumatoid arthritis. Arthritis Rheum. 1998:41:1552-63.

21. Westhovens R, Yocum D, Han J, Berman A, Strusberg I, Geusens P, et al. The safety of infliximab, combined with background treatments, among patients with rheumatoid arthritis and various comorbidities: a large, randomized, placebo-controlled trial. Arthritis Rheum. 2006;54:1075-86. 
22. Zhang F-C, Hou Y, Huang F, Wu D-H, Bao C-D, Ni L-Q, et al. Infliximab versus placebo in rheumatoid arthritis patients receiving concomitant methotrexate: a preliminary study from China. APLAR J Rheumatol. 2006;9:127-30.

23. Abe T, Takeuchi T, Miyasaka N, Hashimoto H, Kondo H, Ichikawa Y, et al. A multicenter, double-blind, randomized, placebo controlled trial of infliximab combined with low dose methotrexate in Japanese patients with rheumatoid arthritis. J Rheumatol. 2006;33:37-44.

24. Lipsky PE, van der Heijde DM, St Clair EW, Furst DE, Breedveld FC, Kalden JR, et al. Infliximab and methotrexate in the treatment of rheumatoid arthritis. Anti-Tumor Necrosis Factor Trial in Rheumatoid Arthritis with Concomitant Therapy Study Group. N Engl J Med. 2000;343:1594-602.

25. Schiff M, Keiserman M, Codding C, Songcharoen S, Berman A, Nayiager S, et al. Efficacy and safety of abatacept or infliximab vs placebo in ATTEST: a phase III, multi-centre, randomised, double-blind, placebo-controlled study in patients with rheumatoid arthritis and an inadequate response to methotrexate. Ann Rheum Dis. 2008;67:1096-103.

26. St Clair EW, van der Heijde DM, Smolen JS, Maini RN, Bathon JM, Emery P, et al. Combination of infliximab and methotrexate therapy for early rheumatoid arthritis: a randomized, controlled trial. Arthritis Rheum. 2004;50:3432-43.

27. Quinn MA, Conaghan PG, O'Connor PJ, Karim Z, Greenstein A, Brown A, et al. Very early treatment with infliximab in addition to methotrexate in early, poor-prognosis rheumatoid arthritis reduces magnetic resonance imaging evidence of synovitis and damage, with sustained benefit after infliximab withdrawal: results from a twelve-month randomized, doubleblind, placebo-controlled trial. Arthritis Rheum. 2005;52:27-35.

28. Marzo-Ortega H, McGonagle D, Jarrett S, Haugeberg G, Hensor E, O'Connor $P$, et al. Infliximab in combination with methotrexate in active ankylosing spondylitis: a clinical and imaging study. Ann Rheum Dis. 2005;64:1568-75.

29. Van Den Bosch F, Kruithof E, Baeten D, Herssens A, de Keyser F, Mielants H, et al. Randomized double-blind comparison of chimeric monoclonal antibody to tumor necrosis factor alpha (infliximab) versus placebo in active spondylarthropathy. Arthritis Rheum. 2002;46:755-65.

30. Plasencia C, Pascual-Salcedo D, Nuno L, Bonilla G, Villalba A, Peiteado D, et al. Influence of immunogenicity on the efficacy of long-term treatment of spondyloarthritis with infliximab. Ann Rheum Dis. 2012;71:1955-60.

31. Wolbink GJ, Vis M, Lems W, Voskuyl AE, de Groot E, Nurmohamed MT, et al. Development of anti-infliximab antibodies and relationship to clinical response in patients with rheumatoid arthritis. Arthritis Rheum. 2006;54:711-5.

32. Baert F, Noman M, Vermeire S, Van Assche G, DH G, Carbonez A, et al. Influence of immunogenicity on the long-term efficacy of infliximab in Crohn's disease. N Engl J Med. 2003;348:601-8.

\section{Submit your next manuscript to BioMed Central and we will help you at every step:}

- We accept pre-submission inquiries

- Our selector tool helps you to find the most relevant journal

- We provide round the clock customer support

- Convenient online submission

- Thorough peer review

- Inclusion in PubMed and all major indexing services

- Maximum visibility for your research

Submit your manuscript at www.biomedcentral.com/submit 